\title{
Multidrug-Resistant Bacteria and Disease Progression in Patients with End-Stage Liver Disease and after Liver Transplantation
}

\author{
Kilian Friedrich ${ }^{1}$, Jessica Krempl ${ }^{1}$, Shigehiko Schamoni ${ }^{2}$, Theresa Hippchen ${ }^{1}$, Jan Pfeiffenberger ${ }^{1}$, Christian Rupp ${ }^{1}$, \\ Daniel Nils Gotthardt ${ }^{1}$, Philip Houben ${ }^{3}$, Rebecca von Haken ${ }^{4}$, Alexandra Heininger ${ }^{5}$, Thorsten Brenner ${ }^{4}$, Arianeb \\ Mehrabi $^{3}$, Karl Heinz Weiss ${ }^{1}$, Markus Mieth ${ }^{3}$
}

\author{
1) Department of Internal \\ Medicine IV, University \\ Hospital of Heidelberg, \\ Heidelberg \\ 2) Department of \\ Computational Linguistics, \\ University of Heidelberg, \\ Heidelberg \\ 3) Department of General, \\ Visceral and Tansplant \\ Surgery, University Hospital of \\ Heidelberg, Heidelberg \\ 4) Department of \\ Anaesthesiology, University \\ Hospital of Heidelberg, \\ Heidelberg \\ 5) Department of Infectious \\ Diseases, Medical \\ Microbiology and Hygiene, \\ Division Hospital and \\ Environmental Hygiene, \\ Heidelberg University \\ Hospital, Heidelberg, \\ Germany
}

Address for correspondence:

Markus Mieth

Im Neuenheimer Feld 110,

69120 Heidelberg,

Germany

Markus.Mieth@med.uni-

heidelberg.de

Received: 03.01.2019

Accepted: 13.07.2019

\section{ABSTRACT}

Background: Multidrug-resistant (MDR) pathogens represent an emerging challenge in end-stage liver disease and in liver transplant recipients.

Methods: We evaluated the impact of MDR bacteria upon clinical outcomes in patients with end-stage liver disease $(n=777)$ at the time of enrollment on the liver transplant (LTx) waiting list, after first LTx $(n=645)$, and after second LTx $(\mathrm{n}=128)$.

Results: Colonization/infection with MDR bacteria was present in 72/777 patients on the waiting list, in 98/645 patients at first LTx, and in 46/128 patients at second LTx. While on the LTx waiting list, the time until first hydropic decompensation ( $\mathrm{p}=0.021)$, hepatic encephalopathy $(\mathrm{p}<0.001)$ and hepatorenal syndrome $(\mathrm{p}$ $<0.001$ ) was reduced in the presence of MDR bacteria, which remained an independent risk factor of poor survival in multivariate analysis $(\mathrm{p}<0.001)$. Following first and second liver transplant, MDR bacteria were associated with an increased risk of infection-related deaths (first LTx: $p<0.001$; second LTx: $p=0.037$ ) and reduced actuarial survival (first LTx: $\mathrm{p}<0.001$; second LTx: $\mathrm{p}=0.046$ ).

Conclusions: We showed that MDR pathogens are associated with poor outcomes before, after first and after recurrent LTx.

Key words: liver transplant - end-stage liver disease - actuarial survival free of liver transplant - multidrug - resistant pathogens.

Abbreviations: ESBL: extended-spectrum $\beta$-lactamase; ESLD: end-stage liver disease; KRINKO: German Commission for Hospital Hygiene and Infection Prevention; LTx: liver transplant; MDR: multidrug-resistant; MELD: model of end-stage liver disease; MGNB: MDR gram-negative bacteria; MRSA: methicillin-resistant Staphylococcus aureus; SBP: spontaneous bacterial peritonitis; VRE: vancomycin-resistant enterococci.

\section{INTRODUCTION}

Patients with liver cirrhosis have a diminished immune function and are susceptible to bacterial infection, sepsis, and death $[1,2]$. In end-stage liver disease (ESLD), bacterial infections are common causes of hepatic decompensation. Over the last two decades, gradual epidemiological changes have occurred, resulting in a shift from gram-negative bacilli toward gram-positive cocci [3-5]. Furthermore, various multidrugresistant (MDR) pathogens have emerged as relevant causes of infection. Epidemiology and antimicrobial resistance patterns follow distinct geographic differences, with extended-spectrum $\beta$-lactamase (ESBL)-producing Enterobacteriaceae being prominent in Southern Europe and Asia, and methicillinresistant Staphylococcus aureus (MRSA) being prevalent in the United States [6]. End-stage liver disease represents the final path of various hepatic diseases, ultimately resulting in the need for a liver transplant (LTx) and enrollment on a LTx waiting list [7].

As patients in need of LTx highly exceed the number of available donor organs, proper management of patients with end-stage liver disease (ESLD) on the LTx list is crucial. These patients are prone to infection, requiring recurrent antimicrobial therapy and hospitalization until the model of end-stage liver disease (MELD) score required for LTx is reached. As the prevalence of MDR pathogens has gradually increased over the past two decades, MDR-related bacteria pose an increasing challenge when treating ESLD patients awaiting 
LTx. Patients with cirrhosis are increasingly becoming infected with MDR bacteria, which in turn lead to high mortality rates in patients with advanced liver disease [3]. The presence of MDR bacteria in patients with liver cirrhosis has been shown to be associated with increased mortality [8]. In LTx recipients, bacterial infections are the leading cause of morbidity and mortality [9]. More than 50\% of LTx recipients develop an infection within the first year after transplantation [10].

In the present study, we investigated the impact of MDR bacteria upon hepatic decompensation and survival in a large cohort of patients with ESDL starting from three different time-points: (a) time of enrollment at Eurotransplant, (b) after first LTx, and (c) after second LTx.

\section{METHODS}

\section{Study design}

Clinical data were retrospectively analyzed, from January 1994 until July 2015, starting from enrollment for LTx at Eurotransplant. Informed consent to participate in the study was obtained from each patient. The study was approved by the Ethical Committee of Heidelberg and carried out in accordance with the Declaration of Helsinki in its present form.

In the LTx waiting list study cohort, we analyzed 777 patients, starting from their date of enrollment at Eurotransplant, between 1994 and 2015, by chart review. Infections, colonization, and clinical characteristics were assessed retrospectively. In the first LTx cohort, 645 patients underwent LTx between 1994 and 2015 and were analyzed for MDR microbes. Clinical data were retrospectively analyzed starting at the time of LTx. In the second LTx cohort, 128 patients who had undergone second LTx (Re-Ltx) between 1994 and 2015 were analyzed for MDR microbes. Clinical data were retrospectively analyzed starting at the time of Re-LTx. At the time of LTx/Re-LTx, there was no evidence of any systemic infection and no evidence of positive blood culture.

\section{Microbial screening and study protocol of antimicrobial management}

In the LTx waiting list cohort, patients were assigned to subgroups (patients with MDR pathogens and patients without MDR pathogens) based on the microbial findings prior to enrollment at Eurotransplant.

Patients on the LTx waiting list were routinely examined every three months at our outpatient clinic. During each outpatient visit, swab analysis (nose and peri-anal swabs) was performed. If patients admitted to our hospital were on the LTx list, routine swab analysis was performed each time. If, upon clinical examination or based on serological findings, systemic infection was suspected, samples of blood cultures, urine, and pulmonary secretions were routinely obtained and analyzed, while bile, abscess fluid, and ascites were only analyzed for bacterial growth if patients had ascites or known abscesses, or if endoscopic retrograde cholangiography was performed.

All MDR data obtained for analysis in the LTx/Re-LTx cohort were gathered during a time period ranging from -5 days prior to LTx/Re-LTx or at LTx/Re-LTx. All patients were routinely swabbed (nose and peri-anal swabs) for MDR pathogens prior to LTx/Re-LTx and at admission to the ICU after the procedure. At the time of LTx/Re-LTx, there was no evidence of any systemic infection and no evidence of positive blood culture in any of the patients.

Hepatic decompensation, infection-related death, and actuarial survival

Hepatic decompensation of patients on the LTx list was assessed by documenting the occurrence of hydropic decompensation requiring paracentesis or forced diuretic treatment, spontaneous bacterial peritonitis (ascites neutrophils $>250 / \mathrm{mm}^{3}$ ), hepatic encephalopathy $\geq$ grade II, according to West Haven Criteria, and hepatorenal syndrome, according to EASL guidelines [11]. Infection-related death was defined as mortality due to sepsis or its complications. Actuarial survival free of LTx was defined using death, LTx, 2nd LTx or 3rd LTx as endpoints.

\section{Microbial multidrug-resistance analysis}

The material was obtained following internal standard operating procedures and delivered to the microbiology laboratory after rapid collection and was cultured aerobically and anaerobically according to standard laboratory protocols. In short, clinically relevant infection and colonization with MDR bacteria were considered risk factors. Infection was defined as clinically documented infection with plausible bacterial growth in cultures of collected materials. Samples of blood cultures, urine, pulmonary secretions, bile, and other substances, such as abscess fluid and ascites, were analyzed for bacterial growth. The analysis of susceptibility to antibiotics commonly used for treatment included results for all isolates. For further analysis, we categorized the samples into groups, according to the bacterial findings, as sterile, low-grade pathogens, non-MDR pathogens, or MDR bacteria, which included all samples containing at least one MDR strain. MDR bacteria were distinguished between vancomycin-resistant enterococci (VRE), MRSA, ESBL, and MDR gram-negative bacteria (MRGN) according to the recommended criteria of the German Commission for Hospital Hygiene and Infection Prevention (KRINKO) [12]. Colonization data were collected retrospectively by the evaluation of nose and peri-anal swabs, which were part of routine hygiene instructions. Swab samples were collected according to standard operating procedures and were analyzed in the microbiology laboratory. Colonization with MDR bacteria was confirmed by the growth of VRE, MRSA, and MRGN according to the KRINKO criteria.

\section{The KRINKO criteria}

The KRINKO recommends a classification of MRGN according to their resistance into four classes of antibiotic drugs: beta-lactam antibiotics, cephalosporins, carbapenems, and fluoroquinolones. Resistance to leading compounds of these four groups was analyzed. Resistance to piperacillin was representative for beta-lactam antibiotics, cefotaxime and/or ceftazidime for cephalosporins, meropenem and/or imipenem for carbapenem, and ciprofloxacin for fluoroquinolone. Resistance to three of these four groups was classified as 3-MRGN. Resistance to all four groups or to carbapenemase-producing bacteria was classified as 4-MRGN. The KRINKO criteria do not consider the different types of beta-lactamases [12]. 


\section{Statistical analysis}

One-way analysis of variance (ANOVA) was performed to compare the means of two or more groups for continuous numerical data. Preliminary testing for normality was conducted by using the Shapiro-Wilk test. If the preliminary test for normality was not significant, then the $t$ test was used; if the preliminary test rejected the null hypothesis of normality, then a nonparametric test (Mann-Whitney's U test) was applied in the main analysis [13]. Spearman's rho was used as the nonparametric measure of statistical dependence between two variables. The rate of actuarial survival free of LTx was estimated using the Kaplan-Meier method. Differences between the actuarial estimates were analyzed using the log-rank test.

The following variables were selected for univariate analysis based on knowledge and findings from previous studies: age at time of enrollment at Eurotransplant, gender, body-mass index (BMI), MELD score at time of enrollment at Eurotransplant, and the presence of MDR. A significance level $<0.10$ at univariate analysis was defined for variables to be included in Cox's proportional hazards model, using a stepwise procedure with a threshold of 0.05 .

\section{RESULTS}

\section{Patients on LTx waiting list}

Of the 777 patients with ESLD, 256 were female (32.9\%) and 521 were male $(67.0 \%)$. The underlying liver diseases contributing to enrollment on the LTx list were: alcoholic liver disease (ALD) $(31.14 \%, \mathrm{n}=242)$, chronic hepatitis B virus (HBV) infection $(6.56 \%, n=51)$, chronic hepatitis $\mathrm{C}$ virus (HCV) infection $(18.27 \%, \mathrm{n}=142)$, primary sclerosing cholangitis (PSC) $(15.05 \%, \mathrm{n}=117)$, non-alcoholic steatohepatitis (NASH) $(7.97 \%$, $\mathrm{n}=62)$, and other hepatic disorders $(20.97 \% \mathrm{n}=163)$. The mean MELD score at the time of enrollment at Eurotransplant was $14.24 \pm 7.9$ (range: $5.0-44.0$ ), while the mean age was $49.1 \pm 11.4$ years (range: $18.0-68.0$ ). Mean follow-up time was 19.4 \pm 23.9 months (range: $0-146.5$ ).

Multidrug resistant bacteria in patients on the LTx waiting list

Of the 777 patients enrolled at Eurotransplant, 72 (9.26\%) had MDR at the time of enrollment at Eurotransplant (Fig.

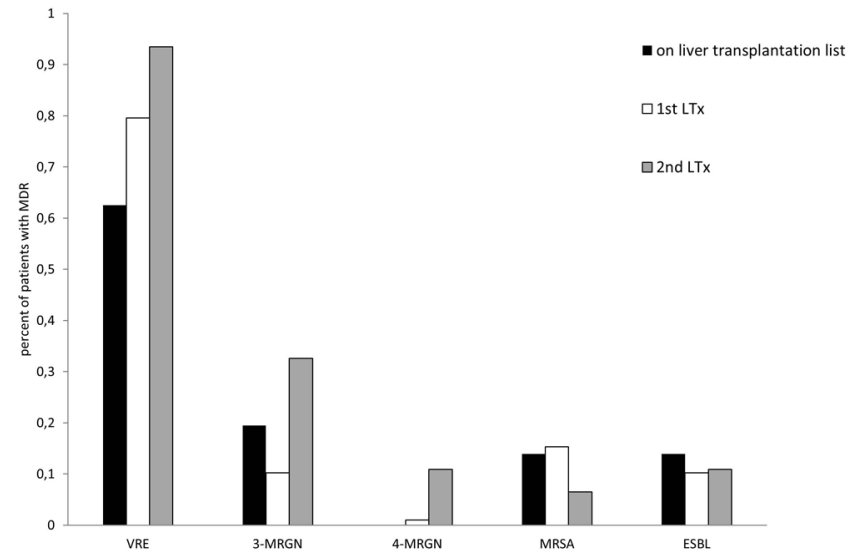

Fig. 1. Multidrug-resistant bacteria in patients on liver transplantation list and in patients after $1^{\text {st }}$ and $2^{\text {nd }} \mathrm{Ltx}$.

1). Of these 72 patients, 49 had MDR identified by swab analysis (rectal, skin, nose) without evidence of systemic infection, while 23 had systemic MDR infection (urinary: $\mathrm{n}$ $=12$, pulmonary: $\mathrm{n}=5$, others: $\mathrm{n}=6$ ). Of the 72 patients with MDR, 45 had VRE, 14 had 3-MRGN, none had 4-MRGN, 10 had MRSA, and 10 had ESBL. Note that seven patients were infected with more than one MDR pathogen. The mean time on the LTx waiting list was $38.7( \pm 38.1)$ months for patients without MDR. Of these 705 patients, 31 died (4.3\%), while 459 (65.1\%) received LTx. The mean time on the LTx waiting list was $21.0( \pm 32.8)$ months for patients with MDR. Of these, five patients died (6.4\%), while 67 (87.0\%) received a transplant.

Clinical outcome of patients with MDR bacteria on the LTx waiting list

Clinical baseline characteristics of patients with or without MDR bacteria on the LTx waiting list are shown in Table I. Regarding laboratory parameters determined at the time of enrollment at Eurotransplant, only serum albumin levels were slightly lower in patients with MDR bacteria compared to albumin levels in patients without MDR bacteria ( $\mathrm{p}=$ 0.024, Supplementary Table I). Otherwise, there were no differences between the two groups at the time of enrollment at Eurotransplant (Supplementary Table I).

Table I. Baseline characteristics of patients with and without MDR bacteria at time of enrolment at Eurotransplant (ET)

\begin{tabular}{lccc}
\hline & No MDR & MDR & p-value \\
\hline Age at enrolment at ET [years], mean \pm standard deviation & $50.2 \pm 11.8$ & $53.2(19.5-68.1)$ & 0.106 \\
Gender, male/female & $471 / 234$ & $50 / 22$ & 0.695 \\
Metabolic co-disease $(\%)$ & $344(705)$ & $45(72)$ & 0.027 \\
Alcoholic liver disease, n (\%) & $215(88.8 \%)$ & $27(11.1 \%)$ & n.a. \\
Viral hepatitis, n (\%) & $169(87.5 \%)$ & $24(12.4 \%)$ & n.a. \\
Primary sclerosing cholangitis, n (\%) & $113(96.5 \%)$ & $4(3.4 \%)$ & n.a. \\
NASH, n (\%) & $57(91.9 \%)$ & $5(8.0 \%)$ & n.a. \\
Other liver diseases, n (\%) & $151(92.6 \%)$ & $12(7.3 \%)$ & n.a. \\
MELD-Score at enrolment ET, mean \pm standard deviation & $14.0 \pm 7.7$ & $15.9 \pm 9.2$ & 0.065 \\
\hline
\end{tabular}

MDR: multidrug-resistant; MELD: model of end-stage liver disease; NASH: non-alcoholic steatohepatitis; ${ }^{*}$ defined as diabetes mellitus type I and II, arterial hypertension, hypercholesterinemia, hypertrigliceridemia; n.a., not applicable 
Regarding hepatic decompensation, time until hydropic decompensation (Fig. 2A, p = 0.021), time until first episode of overt hepatic encephalopathy (Fig. 2C, p < 0.001) and time until first episode of hepatorenal syndrome (Fig. 2D, p < 0.001) were all significantly reduced for patients with MDR at time of enrollment at Eurotransplant compared to patients without MDR. However, time until first episode of spontaneous bacterial peritonitis was not statistically different between the two groups ( $\mathrm{p}=0.383$; Fig. 2B; for detailed survival analysis see Supplementary Table I).

As a result of this, overall actuarial survival free of LTx was significantly reduced for patients with MDR (11.5 \pm 2.2 months; $95 \%$ confidence interval [CI]: $4.3-6.2)$ compared to patients without MDR (35.1 \pm 2.1 months; $95 \%$ CI: 30.9 - 39.4; $\mathrm{p}=0.000$; Fig. 3).

For patients with MDR, there was no difference in actuarial survival between those with systemic MDR infection (12.3 \pm 2.1 months; 95\% confidence interval [CI]: 8.1-16.5) and those with MDR identified by swab analysis (13.6 \pm 2.4 months; $95 \%$ CI: 8.7-18.4; $\mathrm{p}=0.953)$.
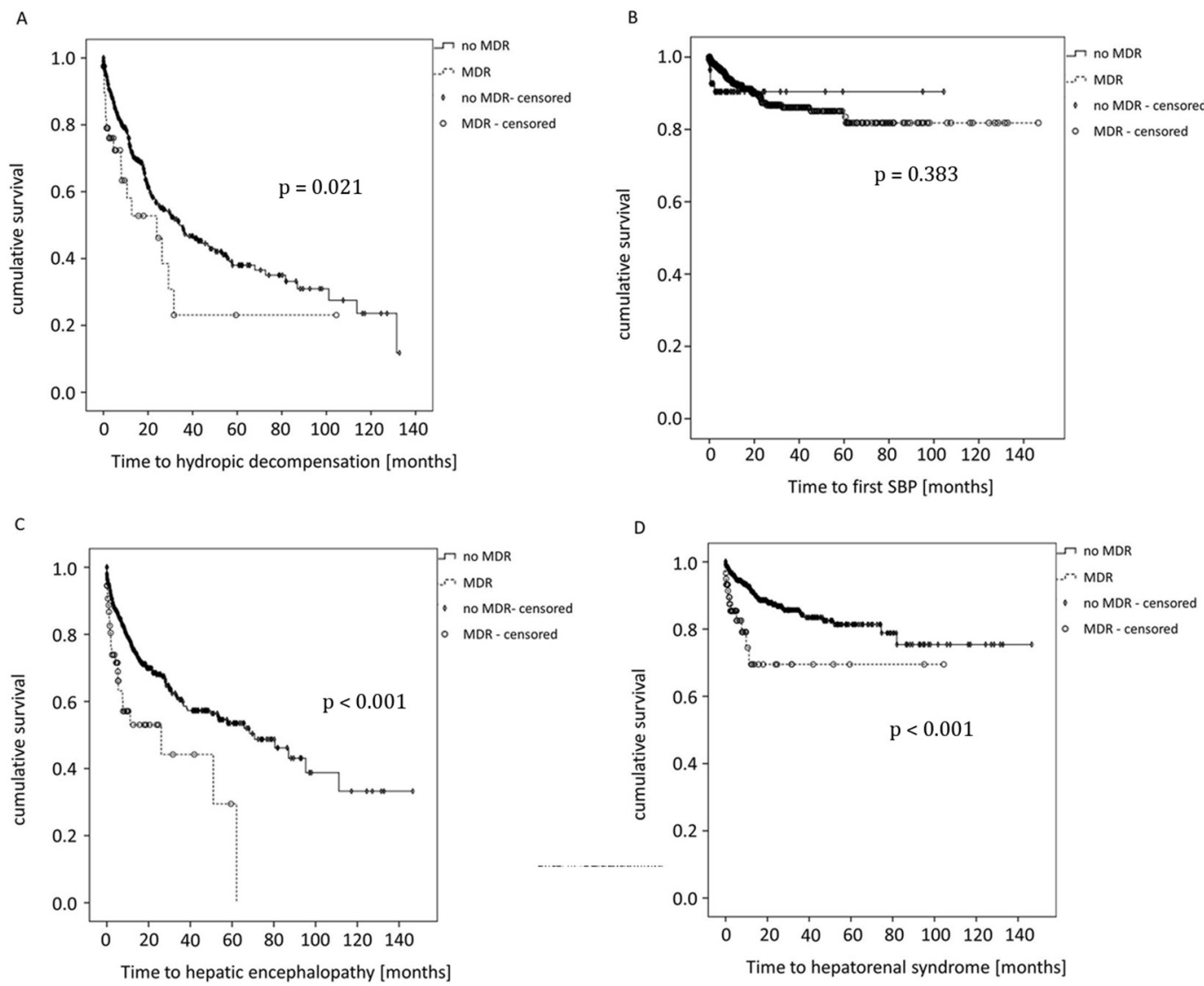

Fig. 2. Time until hepatic decompensation in MDR and non-MDR patients on liver transplantation list (KaplanMeier analysis). A) Time to first hydropic decompensation in patients with end-stage liver disease on liver transplantation list was significantly reduced for patients with MDR compared to patients witout MDR ( $\mathrm{p}=0.021)$. B) Time to first spontaneous bacterial peritonitis in patients with end-stage liver disease on liver transplantation list did not differ patients with MDR compared to patients witout MDR ( $\mathrm{p}=0.383)$. C) Time until hepatic encephalopathy in patients with end-stage liver disease on the liver transplantation list was significantly reduced for patients with MDR compared to patients witout MDR $(p<0.001)$. D) Time until hepatorenal syndrome in patients with end-stage liver disease on the liver transplantation list was significantly reduced for patients with MDR compared to patients witout MDR ( $\mathrm{p}<0.001)$.
Age at time of enrollment at Eurotransplant, gender, BMI, metabolic co-disease, MELD score at time of enrollment, and presence of MDR were subjected to Cox univariate analysis (Table II). Age at time of enrollment, gender, BMI, metabolic co-disease, MELD score at time of enrollment, and the presence of MDR were below the set $\mathrm{p}$-value of 0.1 and were therefore subjected to further multivariate analysis. In multivariate analysis, the presence of MDR remained an independent risk factor associated with reduced actuarial survival free of LTx, along with the MELD score at time of enrollment, metabolic co-disease, gender, and age at enrollment (Table II).

\section{First LTx cohort}

Of the 645 patients who received LTx, 204 were female $(31.6 \%)$ and 441 were male $(68.3 \%)$. The underlying hepatic diseases contributing to LTx were as follows: ALD (23.72\%, $\mathrm{n}=153), \operatorname{HBV}(7.75 \%, \mathrm{n}=50), \operatorname{HCV}(19.22 \%, \mathrm{n}=124)$, PSC $(16.12 \%, \mathrm{n}=104)$, NASH $(8.83 \%, \mathrm{n}=57)$, and other hepatic diseases $(24.34 \%, \mathrm{n}=157)$. Mean follow-up time was 33.4 \pm 51.1 months (range: 0.3 - 291.8; Table III). 


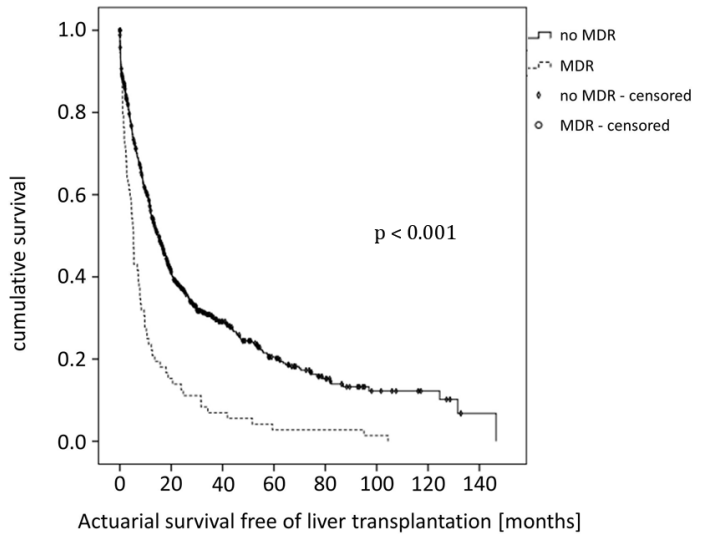

Fig. 3. Kaplan-Meier analysis of actuarial survival free of liver transplantation in patients with end-stage liver disease on the liver transplantation list. There were 490 events in patients without MDR and 72 events in patients with MDR. Actuarial survival was significantly reduced for patients with MDR compared to patients witout MDR $(\mathrm{p}<0.001)$.

Table II. Features associated with death/Ltx in patients on liver transplant list according to Cox's proportional hazards model.

\begin{tabular}{lcc}
\hline & Cox univariate analysis & Cox multivariate analysis \\
& OR $[95 \% \mathrm{CI}]$ & OR $[95 \% \mathrm{CI}]$ \\
\hline Age at enrolment & $1.01[1.00-1.02]$ & $1.02[1.00-1.03]$ \\
ET & $\mathrm{p}=0.001$ & $\mathrm{p}=0.003$ \\
Gender & $1.32[1.10-1.59]$ & $1.33[1.01-1.75]$ \\
& $\mathrm{p}=0.002$ & $\mathrm{p}=0.041$ \\
BMI (per kg/m $\left.{ }^{2}\right)$ & $1.01[0.99-1.04]$ & $0.99[0.96-1.01]$ \\
& $\mathrm{p}=0.08$ & $\mathrm{p}=0.521$ \\
Metabolic co- & $1.32[1.10-1.59]$ & $1.37[1.05-1.78]$ \\
disease & $\mathrm{p}=0.002$ & $\mathrm{p}=0.017$ \\
MELD-Score at & $1.10[1.08-1.11]$ & $1.08[1.06-1.11]$ \\
enrolment ET & $\mathrm{p}<0.001$ & $\mathrm{p}<0.001$ \\
MDR present & $2.21[1.72-2.84]$ & $2.19[1.51-3.17]$ \\
& $\mathrm{p}=0.008$ & $\mathrm{p}<0.001$ \\
\hline
\end{tabular}

ET: Eurotransplant; BMI: body-mass index

Multidrug resistant bacteria in patients after first LTx

Of the 645 patients who received LTx, 98 (15.19\%) had MDR at the time of transplantation. Of these 98 patients, 76 had MDR identified by swab analysis (rectal, skin, nose) without evidence of systemic infection, while 22 had systemic MDR infection (urinary: $\mathrm{n}=8$, bile: $\mathrm{n}=4$, others: $\mathrm{n}=10$ ). Of the 98 patients with MDR, 78 had VRE, 10 had 3-MRGN, one had 4-MRGN, 15 had MRSA, and 10 had ESBL. Note that 14 patients were infected with more than one MDR pathogen.

\section{Clinical outcome of patients with MDR bacteria after first LTx}

Seven days after LTx, there was no difference regarding baseline laboratory parameters, between patients with or without MDR (Supplementary Table II). However, patients with MDR had to stay significantly longer in the ICU following first LTx compared to patients without MDR (Table III). There was no significant difference between non-ICU hospital stays in the two groups (Table III). Defining infection-related death as an endpoint, Cox univariate analysis showed significantly reduced infection-free survival for patients with MDR compared to patients without MDR after first LTx $(\mathrm{OR}=2.10$, 95\% CI: 1.39 $3.19 ; \mathrm{p}<0.001)$. This also resulted in reduced overall actuarial survival, defined as death or Re-LTx, for transplanted patients with MDR compared to patients without MDR (OR=2.24, 95\% CI: $1.65-3.04 ; \mathrm{p}<0.001)$. In MDR patients, survival did not differ between those with MDR colonization and those with MDR infection $(\mathrm{OR}=0.83,95 \% \mathrm{CI}: 0.43-1.62 ; \mathrm{p}=0.596)$.

Table III. Baseline characteristics of patients after liver transplantation (Ltx) with and without multidrug-resistant bacteria (MDR).

\begin{tabular}{lccc}
\hline & No MDR & MDR & p-value \\
\hline $\begin{array}{l}\text { Age at Ltx [years], mean } \pm \\
\text { standard deviation }\end{array}$ & $48.8 \pm 15.3$ & $50.8 \pm 11.0$ & 0.116 \\
$\begin{array}{l}\text { Gender, male/female } \\
\text { Metabolic co-disease }\end{array}$ & $370 / 177$ & $71 / 27$ & 0.346 \\
number) & $286(547)$ & $57(98)$ & 0.283 \\
$\begin{array}{l}\text { ICU stay (days) post Ltx, mean } \\
\pm \text { standard deviation }\end{array}$ & $17.5 \pm 21.8$ & $30.7 \pm 39.7$ & $<0.001$ \\
$\begin{array}{l}\text { Hospital non-ICU stay (days) } \\
\text { post Ltx, mean } \pm \text { standard } \\
\text { deviation }\end{array}$ & $21.5 \pm 15.9$ & $25.7 \pm 19.1$ & 0.055 \\
\hline
\end{tabular}

ICU: intensive care unit; ${ }^{*}$ defined as diabetes mellitus type I and II, arterial hypertension, hypercholesterolemia, hypertriglyceridemia

\section{Second LTx cohort}

Of the 128 patients who received Re-LTx, 48 were female (37.2\%) and 81 were male (62.7\%). The underlying hepatic diseases contributing to Re-LTx were as follows: ALD (18.75\%, $\mathrm{n}=24), \operatorname{HBV}(8.59 ; \mathrm{n}=11), \operatorname{HCV}(27.34 \%, \mathrm{n}=35)$, PSC (14.06\%, $\mathrm{n}=18)$, NASH $(7.03 \%, \mathrm{n}=9)$, and other hepatic disorders $(25 \%$, $\mathrm{n}=32$ ). Mean follow-up time was $35.5 \pm 55.3$ months (range: $0.0-307.9)$.

Multidrug resistant bacteria in patients after second LTx

Of the 128 patients who received second Ltx, 46 had MDR at the time of transplantation. Of these 46 patients, 25 had MDR identified by swab analysis without evidence of systemic infection, while 21 had systemic MDR infection (urinary: $\mathrm{n}=3$, bile: $\mathrm{n}=5$, pulmonary: $\mathrm{n}=3$, others: $\mathrm{n}=$ 10). Of the 46 patients with MDR, 43 had VRE, 15 had 3-MRGN, five had 4-MRGN, three had MRSA, and five had ESBL. Note that six patients were infected with more than one MDR pathogen.

\section{Clinical outcome of patients with MDR bacteria after Re-LTx \\ Baseline laboratory parameters seven days after Re-} LTx did not differ between patients with or without MDR (Supplementary Table III). There was a non-significant trend toward prolonged ICU stay following Re-LTx for patients with MDR (Table IV). Non-ICU hospital stay also did not differ between the two groups (Table IV). Defining infectionrelated death as an endpoint, Cox univariate analysis showed significantly reduced infection-free survival for patients with MDR compared to patients without MDR after first LTx $(\mathrm{OR}=1.73$, 95\% CI: 1.039-2.91; $\mathrm{p}=0.037)$. This also resulted 
in reduced overall actuarial survival, defined as death or third LTx, for re-transplanted patients with MDR compared to patients without MDR (OR=1.68, 95\% CI: 1.00-2.79; $\mathrm{p}=0.046)$. In MDR patients, survival did not differ between patients with MDR colonization and patients with $\mathrm{MDR}$ infection $(\mathrm{OR}=1.54$, 95\% CI: 0.71-3.31; $\mathrm{p}=0.269$ ).

Table IV. Baseline characteristics of patients after second liver transplantation (Ltx) with and without multidrug-resistant bacteria (MDR)

\begin{tabular}{lccc}
\hline & No MDR & MDR & $\mathrm{p}$-value \\
\hline $\begin{array}{l}\text { Age at Ltx [years], mean } \pm \\
\text { standard deviation }\end{array}$ & $45.6 \pm 15.7$ & $52.3 \pm 7.8$ & $\mathrm{p}=0.008$ \\
$\begin{array}{l}\text { Gender, male/female } \\
\begin{array}{l}\text { Metabolic co-disease } \\
\text { number) }\end{array}\end{array}$ & $48 / 35$ & $33 / 13$ & $\mathrm{p}=0.118$ \\
$\begin{array}{l}\text { ICU stay (days) post Ltx, mean } \\
\pm \text { standard deviation }\end{array}$ & $43(83)$ & $26(46)$ & $\mathrm{p}=0.607$ \\
$\begin{array}{l}\text { Hospital non-ICU stay (days) } \\
\text { post Ltx, mean } \pm \text { standard } \\
\text { deviation }\end{array}$ & $25.7 \pm 15.2$ & $35.8 \pm 38.0$ & $\mathrm{p}=0.123$ \\
\end{tabular}

ICU: intensive care unit; ${ }^{*}$ defined as diabetes mellitus type I and II, arterial hypertension, hypercholesterolemia, hypertriglyceridemia

\section{DISCUSSION}

Patients with ESLD and solid LTx recipients have altered immune capacity resulting in increased susceptibility to infectious diseases $[1,14,15]$. Bacterial infections increase four-fold the mortality and are therefore major determinants of prognosis in cirrhosis [16]. In an era of prolonged waiting times on the LTx list, repeated exposure to antibiotics places LTx candidates and recipients at high risk for both colonization and infection with MDR organisms. In recent years, progressive growth in the incidence of MDR strains has been observed [17].

In our large cohort of ESLD patients awaiting LTx, we evaluated the impact of MDR pathogens upon the further clinical course. We found that the presence of MDR pathogens resulted in a significant survival disadvantage compared to ESLD patients without MDR (Fig. 3). A recent study showed that infections caused by MDR bacteria were associated with a higher incidence of treatment failure, septic shock, and hospital mortality in cirrhotic patients [3]. In the present study, we did not observe that SBP occurred more frequently in patients with MDR awaiting LTx $(p=0.083)$. However, the presence of MDR was associated with a reduced time until hepatic decompensation, hepatic encephalopathy, and hepatorenal syndrome. Indeed, bacterial infections have been reported to precipitate hepatic decompensations and thereby constitute the main cause of death in patients with decompensated cirrhosis [18]. In the present study, the time frame from listing to the occurrence of hepatic complications was longer than that reported in other studies. This can be attributed to a mean lab-MELD score at listing of 14.2 and an overrepresented study population of PSC patients, as we are a reference center for this liver disease entity.

Previous studies have shown that pre-transplant colonization with MDR bacteria leads to a higher risk of postoperative infections $[14,19]$. These infections are caused by the same MDR organisms that have colonized the digestive tract or the oropharynx before LTx $[20,21]$. We found that patients with MDR needed prolonged ICU attention after first LTx $(\mathrm{p}<0.001)$, and there was a trend toward a prolonged ICU stay following second LTx $(p=0.069)$. Furthermore, time until infection-related death was diminished for MDR patients after first LTx $(\mathrm{p}<0.001)$ and second LTx $(\mathrm{p}=0.037)$.

The vulnerability of transplant recipients to infection may lead to increased use of broad-spectrum empiric antibiotics, which in turn contributes to drug resistance selection [22]. Failure to provide appropriate empiric antimicrobial therapy has therefore been described as occurring more frequently in MDR-infected patients [23, 24]. Among other factors, recurrent hospitalization and antibiotic treatment are risk factors for contracting MDR pathogens. MDR strains must be treated with second- or third-line antibiotics, the use of which tends to present major difficulties. Beside less clinical experience in their application and lack of sufficient pharmacokinetic knowledge, these antibiotics had neurological (colistin) and renal (aminoglycosides and colistin) side effects. Renal toxicity can be further increased by the concomitant use of nephrotoxic immunosuppressant drugs, such as calcineurin inhibitors. Second- or third-line antibiotics are usually only available in parenteral formulations, resulting in a prolonged hospital stay, which in turn increases the risk of additional hospital-acquired infections.

Interestingly, the survival disadvantage observed in all three settings (LTx list, post-LTx, post-second LTx) occurred irrespective of whether MDR pathogens were present as systemic infection or colonization. Therefore, one might speculate that the poor survival associated with the presence of MDR pathogens might not be attributable to the infectious pathogen itself, but rather reflects a complex patient history of recurrent antibiotic treatments, an increased number of hospitalizations, or diminished immuno-capacity. However, the presence of MDR pathogens represents a robust predictor of poor survival for patients awaiting LTx, as it remained independent in multivariate analysis (see Table II).

In our study, MDR pathogens were associated with reduced patient survival both before and after LTx. These findings have several implications. First, infection prevention measures and antibiotic stewardship [25] remain of the utmost importance in the emergence and transmission of MDR pathogens and should therefore be incorporated when patients are enrolled on the LTx waiting list. Although studies evaluating antibiotic stewardship programs in organ transplantation are limited [26-28], opportunities for antibiotic stewardship in organ transplantation have been discussed [28]. Previously recommended empirical antibiotic therapies, mainly based on third-generation cephalosporins and amoxicillin/clavulanic acid have been shown to be ineffective in nosocomial infections in up to $60 \%$ of cases $[3,29]$ and must be adapted accordingly. Second, regarding microbial epidemiology, one must keep in mind the broad regional differences between infected patterns [30-32]. LTx patients are likely to become colonized and/ or infected with MDR pathogens frequently isolated in the admition units. Therefore, knowledge of local antimicrobial epidemiology should be obtained in each LTx unit [5]. Empirical treatment of suspected bacterial infections must thus 
include the selection of antimicrobial agents based on local epidemiological data and the patient's history of colonization or infection with antibiotic-resistant organisms.

\section{CONCLUSIONS}

Our study demonstrated that MDR pathogens were associated with poor outcomes before, after first and after recurrent LTx. Infection prevention measures and antibiotic stewardship therefore remain of utmost importance in the management of liver transplanted patients.

Conflicts of interest: The authors declare that they have nothing to disclose regarding funding from industries or conflicts of interest with respect to this manuscript.

Authors' contributions: K.F., K.H.W., M.M., J.K., S.S., T.H., J.P., C.R., D.N.G., P.H. drafted the manuscript. K.F., K.H.W., M.M. were responsible for data collection and statistical analysis. K.F. D.N.G., R.v.H., A.H., T.B., A.M., K.H.W., M.M. edited and revised the manuscript.

Acknowledgements. We thank Mrs. Klöters-Plachky and Mrs. Leopold for their excellent technical assistance.

Supplementary material: To access the supplementary material visit the online version of the J Gastrointestin Liver Dis at http://dx.doi. org/10.15403/jgld-212

\section{REFERENCES}

1. Albillos A, Lario M, Alvarez-Mon M. Cirrhosis-associated immune dysfunction: distinctive features and clinical relevance. J Hepatol 2014;61:1385-1396. doi:10.1016/j.jhep.2014.08.010

2. Acevedo J. Multiresistant bacterial infections in liver cirrhosis: Clinical impact and new empirical antibiotic treatment policies. World $J$ Hepatol 2015;7:916-921. doi:10.4254/wjh.v7.i7.916

3. Fernandez J, Acevedo J, Castro M, et al. Prevalence and risk factors of infections by multiresistant bacteria in cirrhosis: a prospective study. Hepatology 2012;55:1551-1561. doi:10.1002/hep.25532

4. Fernandez J, Navasa M, Gomez J, et al. Bacterial infections in cirrhosis: epidemiological changes with invasive procedures and norfloxacin prophylaxis. Hepatology. 2002;35:140-148. doi:10.1053/jhep.2002.30082

5. Friedrich K, Nussle S, Rehlen T, Stremmel W, Mischnik A, Eisenbach C. Microbiology and resistence in first episodes of spontaneous bacterial peritonitis: implications for management and prognosis. J Gastroenterol Hepatol 2016;31:1191-1195. doi:10.1111/jgh.13266

6. Piano S, Romano A, Rosi S, Gatta A, Angeli P. Spontaneous bacterial peritonitis due to carbapenemase-producing Klebsiella pneumoniae: the last therapeutic challenge. Eur J Gastroenterol Hepatol 2012;24:12341237. doi:10.1097/MEG.0b013e328355d8a2

7. Murray KF, Carithers RL Jr. AASLD practice guidelines: Evaluation of the patient for liver transplantation. Hepatology 2005;41:1407-1432. doi:10.1002/hep.20704

8. Waidmann O, Kempf VA, Brandt C, Zeuzem S, Piiper A, Kronenberger B. Colonisation with multidrug-resistant bacteria is associated with increased mortality in patients with cirrhosis. Gut 2015;64:1183-1184. doi:10.1136/gutjnl-2014-309104
9. Saner FH, Olde Damink SW, Pavlakovic G, et al. Pulmonary and blood stream infections in adult living donor and cadaveric liver transplant patients. Transplantation 2008;85:1564-1568. doi:10.1097/ TP.0b013e31816f61a6

10. Rubin RH. The direct and indirect effects of infection in liver transplantation: pathogenesis, impact, and clinical management. Curr Clin Top Infect Dis 2002;22:125-154.

11. European Association for the Study of the Liver. EASL clinical practice guidelines on the management of ascites, spontaneous bacterial peritonitis, and hepatorenal syndrome in cirrhosis. J Hepatol 2010;53:397-417. doi:10.1016/j.jhep.2010.05.004

12. Hygiene measures for infection or colonization with multidrugresistant gram-negative bacilli. Commission recommendation for hospital hygiene and infection prevention (KRINKO) at the Robert Koch Institute (RKI). Bundesgesundheitsblatt Gesundheitsforschung Gesundheitsschutz 2012:1311-1354. doi:10.1007/s00103-012-1549-5

13. Rochon J, Gondan M, Kieser M. To test or not to test: Preliminary assessment of normality when comparing two independent samples. BMC Med Res Methodol 2012;12:81. doi:10.1186/1471-2288-12-81

14. Zhong L, Men TY, Li H, et al. Multidrug-resistant gram-negative bacterial infections after liver transplantation - spectrum and risk factors. J Infect 2012;64:299-310. doi:10.1016/j.jinf.2011.12.005

15. Mrzljak A, Peric Z, Kovacevic V, Gustin D, Vrhovac R, Andrasevic AT. Rising problem of multidrug-resistant gram-negative bacteria causing bloodstream infections after liver transplantation: how should we handle the issue? Liver Transpl 2010;16:1217-1219. doi:10.1002/lt.22137

16. Arvaniti V, D’Amico G, Fede G, et al. Infections in patients with cirrhosis increase mortality four-fold and should be used in determining prognosis. Gastroenterology 2010;139:1246-1256. doi:10.1053/j. gastro.2010.06.019

17. Aguado JM, Silva JT, Fernandez-Ruiz M, et al. Management of multidrug resistant Gram-negative bacilli infections in solid organ transplant recipients: SET/GESITRA-SEIMC/REIPI recommendations. Transplant Rev (Orlando) 2018;32:36-57. doi:10.1016/j.trre.2017.07.001

18. Jalan R, Fernandez J, Wiest R, et al. Bacterial infections in cirrhosis: a position statement based on the EASL Special Conference 2013. J Hepatol 2014;60:1310-1324. doi:10.1016/j.jhep.2014.01.024

19. Russell DL, Flood A, Zaroda TE, et al. Outcomes of colonization with MRSA and VRE among liver transplant candidates and recipients. Am J Transplant 2008;8:1737-1743. doi:10.1111/j.1600-6143.2008.02304.x

20. Bert F, Bellier C, Lassel L, et al. Risk factors for Staphylococcus aureus infection in liver transplant recipients. Liver Transpl 2005;11:1093-1099. doi:10.1002/lt.20491

21. Bert F, Larroque B, Paugam-Burtz C, et al. Pretransplant fecal carriage of extended-spectrum beta-lactamase-producing Enterobacteriaceae and infection after liver transplant, France. Emerg Infect Dis 2012;18:908916. doi:10.3201/eid1806.110139

22. Santoro-Lopes G, de Gouvea EF. Multidrug-resistant bacterial infections after liver transplantation: an ever-growing challenge. World J Gastroenterol 2014;20:6201-6210. doi:10.3748/wjg.v20.i20.6201

23. de Gouvea EF, Martins IS, Halpern M, et al. The influence of carbapenem resistance on mortality in solid organ transplant recipients with Acinetobacter baumannii infection. BMC Infect Dis 2012;12:351. doi:10.1186/1471-2334-12-351

24. Kim YJ, Yoon JH, Kim SI, et al. High mortality associated with Acinetobacter species infection in liver transplant patients. Transplant Proc 2011;43:2397-2399. doi:10.1016/j.transproceed.2011.06.011

25. Magiorakos AP, Srinivasan A, Carey RB, et al. Multidrug-resistant, extensively drug-resistant and pandrug-resistant bacteria: an 
international expert proposal for interim standard definitions for acquired resistance. Clin Microbiol Infect 2012;18:268-281. doi:10.1111/ j.1469-0691.2011.03570.x

26. Abbo LM, Ariza-Heredia EJ. Antimicrobial stewardship in immunocompromised hosts. Infect Dis Clin North Am 2014;28:263279. doi:10.1016/j.idc.2014.01.008

27. Aitken SL, Palmer HR, Topal JE, Gabardi S, Tichy E. Call for antimicrobial stewardship in solid organ transplantation. Am J Transplant 2013;13:2499. doi:10.1111/ajt.12364

28. So M, Yang DY, Bell C, Humar A, Morris A, Husain S. Solid organ transplant patients: are there opportunities for antimicrobial stewardship? Clin Transplant 2016;30:659-68. doi:10.1111/ctr.12733

29. Friedrich K, Nussle S, Rehlen T, Stremmel W, Mischnik A, Eisenbach C. Microbiology and resistance in first episodes of spontaneous bacterial peritonitis: implications for management and prognosis. J Gastroenterol Hepatol 2016;31:1191-195. doi:10.1111/jgh.13266

30. Gou YZ, Liu B, Pan L, Yu HT, Wang JP, Wang DC. Pathogens of spontaneous bacterial peritonitis change in northern China. Saudi Med J 2010;31:1152-1156.

31. Campillo B, Richardet JP, Kheo T, Dupeyron C. Nosocomial spontaneous bacterial peritonitis and bacteremia in cirrhotic patients: impact of isolate type on prognosis and characteristics of infection. Clin Infect Dis 2002;35:1-10. doi:10.1086/340617

32. Cholongitas E, Papatheodoridis GV, Lahanas A, Xanthaki A, Kontou-Kastellanou C, Archimandritis AJ. Increasing frequency of Gram-positive bacteria in spontaneous bacterial peritonitis. Liver Int 2005;25:57-61. doi:10.1111/j.1478-3231.2004.0985.x 
Supplementary Table I. Laboratory characteristics of patients after liver transplantation with and without multidrug-resistant bacteria

\begin{tabular}{|l|c|c|c|}
\hline & No MDR bacteria & MDR bacteria & p-value \\
\hline $\begin{array}{l}\text { INR 7 days post Ltx, mean } \pm \\
\text { standard deviation }\end{array}$ & $1.3 \pm 0.6$ & $1.1 \pm 0.2$ & $\mathrm{p}=0.633$ \\
\hline $\begin{array}{l}\text { Albumin (g/dI) 7 days post Ltx, } \\
\text { mean } \pm \text { standard deviation }\end{array}$ & $2.7 \pm 1.3$ & $2.6 \pm 0.5$ & $\mathrm{p}=0.249$ \\
\hline $\begin{array}{l}\text { AST (U/I) 7 days post Ltx, mean } \\
\pm \text { standard deviation }\end{array}$ & $110.5 \pm 293.4$ & $91.7 \pm 121.6$ & $\mathrm{p}=0.545$ \\
\hline $\begin{array}{l}\text { ALT (U/I) 7 days post Ltx, mean } \\
\pm \text { standard deviation }\end{array}$ & $251.1 \pm 342.1$ & $191.2 \pm 177.2$ & $\mathrm{p}=0.081$ \\
\hline $\begin{array}{l}\text { Creatinine (mg/dl) 7 days post } \\
\text { Ltx, mean } \pm \text { standard deviation }\end{array}$ & $1.3 \pm 0.9$ & $1.2 \pm 0.6$ & \\
\hline
\end{tabular}

LTx: liver transplant

Supplementary Table II. Laboratory characteristics of patients after second liver transplantation with and without multidrug-resistant bacteria

\begin{tabular}{|l|c|c|c|}
\hline & No MDR bacteria & MDR bacteria & p-value \\
\hline $\begin{array}{l}\text { INR 7 days post Re-Ltx, mean } \pm \\
\text { standard deviation }\end{array}$ & $1.2 \pm 0.3$ & $1.2 \pm 0.2$ & $\mathrm{p}=0.628$ \\
\hline $\begin{array}{l}\text { Albumin (g/dI) 7 days post Re- } \\
\text { Ltx, mean } \pm \text { standard deviation }\end{array}$ & $2.6 \pm 0.5$ & $2.4 \pm 0.3$ & $\mathrm{p}=0.066$ \\
\hline $\begin{array}{l}\text { AST (U/I) 7 days post Re-Ltx, } \\
\text { mean } \pm \text { standard deviation }\end{array}$ & $260 \pm 671,9$ & $226 \pm 327.2$ & $\mathrm{p}=0.149$ \\
\hline $\begin{array}{l}\text { ALT (U/I) 7 days post Re-Ltx, } \\
\text { mean } \pm \text { standard deviation }\end{array}$ & $246.3 \pm 342.1$ & $218.5 \pm 177.2$ & $\mathrm{p}=0.092$ \\
\hline $\begin{array}{l}\text { Creatinine (mg/dl) 7 days post } \\
\text { Re-Ltx, mean } \pm \text { standard } \\
\text { deviation }\end{array}$ & $1.3 \pm 0.7$ & $1.1 \pm 0.6$ & $\mathrm{p}=0.154$ \\
\hline
\end{tabular}

Ltx: liver transplant 